\title{
Public Expenditure for Education and Economic Growth in Vietnam
}

\author{
Thi Thanh Binh Dao* Anh Ngoc Nguyen \\ Hanoi University, Faculty of Management and Tourism, \\ Km 9 Nguyen Trai Road, Thanh Xuan District, Hanoi
}

\begin{abstract}
This research provides empirical evidence of impact of public expenditure for education on economic growth in Vietnam from 2000 to 2015 . In addition, effect of human capital quality is also attacted into the research to examine its impact on economic growth. Specifically, for relating performance of government expenditure for education, we choose enrolment number of pre-primary school, enrolment number of primary school, enrolment number of lower secondary school, enrolment of upper secondary school, percentage of high school graduation as education's performance. Moreover, we aslo estimate the impact of percentage of government expenditure of GDP for health on GDP growth. Firstly, we estimate the relationship of government capital and regular expenditure for education, its performance mentioned above and human capital quality (HDI as proxy). Secondly, we test the impact of all explanatories of model 1 including HDI plus percentage of government expenditure of GDP for health on GDP growth. Consequently, the first model shows that enrolment number of pre-primary school and regular government spending for education have positive relationship with HDI, whereas, capital spending for education shows negative relationship. For the second model, enrolment number of lower secondary school, enrolment number of primary school, capital expenditure of public budget for education, and HDI are related positively to GDP growth. On the other hand, enrolment number of pre-primary school, percentage of high school graduation, and regular spending for education move negatively way with GDP growth.
\end{abstract}

Keywords: HDI, government expenditure, GDP growth, enrolment

DOI: $10.7176 / \mathrm{JESD} / 11-6-06$

Publication date:March $31^{\text {st }} 2020$

\section{Introduction}

Economic growth is defined as an increase in gross domestic products (GDP), or gross national products (GNP), or GDP per capital income in a period of time. Economic growth is definitely closed to basic investment, human capital resource investment, and technological investment. Therefore, to evaluate economic development or standard living of households of every country, policy makers, market participants including investors, financial institutions look at those statistics. In fact, there has been a lot of researchers and policy makers who have been done papers to seek out recommendations and solutions to increase GDP or GNP, one of which is investment for education. Accurately, they have figured out, and proved the relationship between public government budget for education and economic growth (GDP growth).

Recently, both foreign and domestic researchers have claimed that one of the shortest ways to develop economic growth efficiently and stably is public expenditure for education, specifically human capital resources in the period of integration, and intelligence. It is undeniable that education decides quality of citizens of that country, and how their awareness is evolved in the society.

Becker (1993) is one of the earliest researchers who used to pursue education field to develop his career. All his papers he wrote or published follow human capital impacts, including investment in education and rate of returns as well as earnings. Definitely, education has not only played an important role in creating human capital resource contributing GDP growth, but also schooling is rights, and benefits of citizens of every country (Gary Becker, 1993). That is the reason why education is considered as the main objective in growing target and takes up a vast proportion per total government expenditure of developing countries in the world (Omotor, 2004).

According to Cobb-Douglas (1928), production function-two of the most famous original models which illustrated GDP as a function of human capital and labor force, quality of human capital in any nation decides mainly in that country's economic growth. Historically, in the world, there is a lot of theatrical models about economic growth starting with Ricardo (1800s) that concentrated on explaining the relationship between GDP growth and agricultural manufacturing land, however, it was obvious that this work wasn't considered as an optimal work when using only agricultural aspect. Nevertheless, that idea was employed much in further works, typically Lewis model (1952), and Oshima and new classical (1995), namely dual area model. Dual area model is divided into two parts: part 1 is to research the relationship between economic growth and agriculture and industry; part 2 is to explain movement of labor from agriculture to industry, meaning that this kind of model focuses mainly on human capital resources and productivity growth due to investment, and technical science which influence two economic fields. It can be concluded that economic growth depends much on quality of human which is consistent with education. Through education, human can raise awareness, skills, attitude, and gain knowledge essentially. 
Obviously, having better education is equivalent to having a better work as well as better life. And one of the major method to improve education situation is public investment on this with expectation that increase in education's investment will increase quality of labor force, which increases economic growth. Indeed, this issue has been considered for a long time, and many researchers has tried to explain the relationship between public government expenditure and economic growth both international and domestic empirical works. Normally, research of this phenomenon is applied for developing countries to help policy makers to adjust proportion of investment accounts. Besides, the others will depend on research to evaluate the current performance of public government on education.

Besides, another issue associated closely with human capital is health (Weil, 2007). Definitely, it is estimated that there is approximately $3-6 \%$ of working time, $10 \%$ for unemployment, $23.5 \%$ of people on job restricted caused by poor health (Europe Commission, 2013). It is recognized that healthcare contributes in reducing unemployment rate (Europe Commission, 2013). Therefore, public expenditure for health is always a phenomenon that should be considered as essential issue because appropriate health investment strategy leads strong health, obviously, good health makes good human capital qualification, which raises GDP growth. In the world, a huge number of studies has shown the relationship between government expenditure for health and GDP growth. For example, negative relationship between infant mortality rate and GDP per capital and per health expenditure is proved by an India study (World Bank, 2004), which applied for the period of 20 years (from 1980 to 1999) in India. In this paper, the dependent variable is infant mortality rate, and the independent variables are GDP per capital, health expenditure per capital. In general, investment on health is considered as investment on human capital as well as economic growth because of reducing job-poor proportion due to health reason, and increasing working efficiency.

In Vietnam, the government still plays major role in source of capital expenditure for education, health. In fact, these fields account for large proportions in total government budget. Particularly, regarding health, Vietnam is ranked at the second from the bottom (2007) and the fifth from the top (2014) among ASEAN countries on public expenditure per total health expenditure, which increases over period of time (31\% in 2007 and $54.1 \%$ in 2014). However, the difficulty in medical staff at the grassroots level (both shortage and weakness) affects quality of service. The proportion of health insurance coverage for the near poor is still low (55\%), although they are supported over $70 \%$ of insurance's face value. As a result, taking into account health insurance, health makes up $8 \%$ government budget, and 54\% public expenditure including health insurance. Finally, the most important part of this paper is investment for education. Vietnam is one of the countries which spends most for education in ASEAN zone from increasing from $12 \%$ to $20 \%$ per total public expenditure over 12 years (from 1998 to 2010), almost of which is used for regular expenditure like teachers' wages, for example (approximately 82\%), whereas, education spending should include regular, investment and development spending or capital expenditure. Consequently, it can be stated that in Vietnam investment for education qualification improvement is restricted and has not still been attached seriously. However, in spite of spending a lot on education expenditure, its performance is not really good because of lack of transparency in education budget as well as inconsistency in spending structure for each part in schooling. In the scenario of Vietnam's sovereign debt has been at safe ceiling and the budget deficit is always a great pressures maintaining government budget for education as well as health in the coming years will face with many challenges. It is, therefore, necessary to build a relationship between public investment in education, health, and and economic growth in Vietnam, which demonstrates those contributions to economic development and necessary to maintain the rate of public investment structure for each one. There is also a need to study and comparison the effectiveness of investments in education and health, which are the two most invested sectors from the state budget in current scenario of Vietnam. Therefore, the research is necessary to fill the previous works' gap as well as current government budget spending situation in Vietnam. In general, we have tried to established methodology and constructed model to illustrate the relationship between government expenditure for education and economic growth. The result of the model will help policy makers in distributing government budget in accordance with spending structure that should be separated by categories (capital expenditure and regular expenditure), which makes the economy develop stably. Besides, we have also specific purposes. Originally, it is necessary to estimate the impact of government expenditure for education and performance of education on human capital quality before coming to GDP growth as an indirect approach. Then, we estimate and evaluate effect of public expenditure for education, health and human capital quality on GDP growth.

From the above analysis, this paper will be divided into 5 sessions. Session 1 performs the introduction to expenditure structure for each field in Vietnam. Session 2 provides literature review on impacts of investment on education and economic growth on higher education. Particularly, this research illustrates the relationship between education expenditure including spending structure plus education investment performance, and human capital quality represented by HDI. Then, the second model will explain impact of all independent variables of the first model plus HDI and percentage of government expenditure for health per GDP on GDP growth. In addition, it is necessary to show the reason why this topic needs considering and conducted as soon as possible. Session 3 covers methodology to construct this study which includes research question, data and sampling collection, theorical 
models and our models used to estimate regression. After that, session 4 shows quantitative analysis, including descriptive data, regression result and interpretation, hypothesis testing, test error terms and fixed that kind of error if happening. Finally, session 5 represents conclusions, recommendations for both further research and policy makers in create appropriate expenditure budget structure for education and health to maximize GDP growth as well as raise living standard of citizens.

\section{Literature Review}

\subsection{Relationship between Investment for Education, as well as for Health and Economic Growth}

For a long time, public investment for education, or in another word of saying, government expenditure for education has been considered as a key of economic development. Therefore, a lot of famous researchers studied and seeked evidence to prove the correlation between them. There are many kinds of variables representing for investment in education used to explain dependent variable called economic growth measured by GDP growth. For instance, typical explanatories are primary school and secondary school enrollment rate, investment accounts separated into recurrent, research and development spending, or performance of investment for education calculated by percentage of graduation of high school, labor's wage (University of London, 2014). However, independent variables chosen are based on implication of authors as well as application of each work, which is closed to situation, characteristics of sample and sample size. For more details, this paper describes the previous works that tried to explain the relationship between investment in education and GDP growth.

Firstly, one of the earliest research which originates from relationship between investment in education and economic growth idea is Romer (1986). In this paper, the author describes the impacts of knowledge, physical capital, cumulative research and development expenditures, expenditures for education and job training on increasing rate of return and long-run growth. With the point of view original work, the author builds a model to help for further research since partly this model is implied for marginal productivity of knowledge of physical capital development. Then, Lucas (1988), and Mankiw et al., (1992) concentrate on endogenous factor of human capital, one of famous indicators to measure performance of public expenditures, on economic growth, which normally is based on productivity function in neoclassical model of Solow (1956).

Barro (1991) studied a sample of 98 countries from 1960 to 1985, found that besides human capital variables like enrollment rate of primary and secondary school, the author mentions government expenditures for education as a factor influencing GDP per capital. Consequently, there is negative relationship between government investment per GDP and GDP per capital. In addition, the author proves that human capital is significant with economic growth, specifically, positively related. Moreover, to test more completely impacts on GDP growth, the author also mentions some important independent variables such as fertility rate, physical investment to GDP, political situation, and market distortions like high taxes rate. Following that, political stability is related positively to growth rate of GDP, on the other hand, market distortions moves inversely. In general, by disclosing regression results, it is concluded that with rich countries, they have lower rate of fertility, high physical investment to GDP level, and lower level of market distortions. This is useful for further works and policy makers when setting up expenditure structure.

Benhabib and Spiegel (1994) and Pritchett (1996) have tried to test the hypothesis of effects of investment in education on economic growth by applying Cobb-Douglas employed for countries in Euro zone in a period of time. In their model, they use some typical independent variables of performance of human capital investment, which are numbers of schooling years, literacy rate, and secondary enrollment rate that is based on Barro (1991). However, there is still conflict between results when investment in education has no significance or negative relationship with GDP per capital.

Yi and Kocherlakota (1996) used sample of United States from 1881 to 1991 and United Kingdom from 1831 to 1991. As a result, there is enough evidence to conclude that public investment in education, and taxation are related positively and negatively to GDP per capital growth rate, respectively. In the range of that paper, the authors concentrate on R\&D capital that promotes human resources. At the same year, Nonneman and Vanhoud (1996) also prove the relationship between human capital and GDP growth rate. However, there is a quite difference from results between two works when the authors find that there is no significance of human capital in economic growth, which means even there is a lot of money invest into education activities, it is not always same result of positive relationship with GDP per capita. Then, Pritchett (1996) also tests investment in education's influence on economic growth applied for sample size of 86 countries according to panel data with each area because of no significance result. As a consequence, whereas in Asia and Latin zone explanatories affect positively GDP growth, it shows negative relationship in MENA zone which implies Middle East and North Africa countries. It can be said that this is a solution of previous works when they have not approached the impacts of geographical characteristics.

In 2002, Greiner and Semmler combined two approaches of Romer (1986) and Lucas (1988), when considering investment in both physical and knowledge capital. It can be said that investing in knowledge can be taken into account investing in human capital, which means the authors also depend on model of Solow (1956) 
because of mentioning endogenous factors. Firstly, the paper focuses on productivity sector based on CobbDouglas product function that demonstrates relationship between characteristics of labor capital including physical and foundation knowledge because they are key factors raising productivity. Secondly, the authors build model of investment in physical and knowledge called externalities' effect before mentioning household time spending for education. To explain the reason why household time spending is taken into account, the authors show that quality of investment for education increase if parents use more time in taking care of education, which increases GDP per capita. To support for the paper, the authors apply methodology for two countries after world war, Germany and Japan. Particularly, for Germany, data of consumption and investment is collected for the period of 45 years (from 1950 to 1994), while for Japan, the authors only collect data from 1950 to 1992 . As a consequence, both variables are significant after situation that two countries have just overcome world war is explained. To sum up, in the range of that paper, it is concluded that marginal product or GDP per capital growth rate increases following high investment in knowledge capital even low investment in physical capital.

Odekunle (2001) does research to conclude that there is positive relationship between investment in human capital and manufacturing activities and development of technology. Then, Garba (2002) also considers this kind of issue, then, does research employed cross-country section to run regression. Consequently, the author claims that human capital run toward with economic growth. Similarly, investment in education contributes benefits in reducing unemployment rate according to Ayeni (2003). However, it is mentioned reasons why there is difference among results, so when applying the research for Nigeria, Ayara (2002) says no significance. There is a lot of works implied for Nigeria following each stage, which concentrates on mostly impacts of public investment in education and economic growth. Particularly, Ifionu, et al., (2013) do the study for the period of 31 years (from 1981 to 2012) by using Ordinary Least Square (OLS) with growth rate of GDP as a proxy of economic growth and public investment on social services, recurrent government expenditures in education, enrolment rate of primary pupils, and ratio of primary pupils to teacher as explanatories of model. However, there is quite difference in the authors' consideration when government expenditures on services including both investment for health and education, which indicates more efficiently of human capital aspects. As a result, government expenditures on social services, and recurrent public spending for education are significant and positively related to economic growth, whereas, the others show mixed results with dependent variable. That is the reason why it is recommended by the authors that the government should use more budget into social services like health and education.

The role of human capital as well as investment for education on economic growth can be undeniable, proven above. However, normally, investment for health also contributes in productivity, which is considered by a lot of researchers in the world. Investing in health is investing in human capital, and recognized as green growth expenditure (Europe Commission, 2013). Obviously, if people has good healthy, they will do work more efficiently and finish it with high performance, which increases productivity (GDP per capital). However, performance of labor force not only depends on how much government spends, but also how government uses budget. Then, infrastructure also makes up a quite big part of aggregate state's budget.

With time series data, Amponsah (2006) employing Ghana from 1970 to 2004 as sample to find that there is negative relationship between government expenditure and economic growth in long run, but in short run, public investment for health and transportation show an inverse impact on GDP per capital and that of education also move toward to estimated variable. However, with cross country, it will be shown different result, meaning that with each kind of country with political status and characteristics of development, the findings will be mixed. Particularly, in Parkistan, one of urgency market, there is also variety of works related to this issues. For instance, Ghani and Din (2006), Rehman et al., (2010) provide a clue that between government expenditure and economic growth has no relationship. In fact, public investment should include education, health, and public transportation infrastructure which play main role in increasing productivity of the whole country.

Campodonico et al., (2014) test impact of public investment in education, health, and infrastructure on economic growth, as well as income distribution in Peru. Specifically, with consideration of government budget, unemployment rate, reducing poverty, and budget structure of state, group of authors use Dynamic Computable General Equilibrium Model (DCGEM), which is an economy-wide model and describes the relationship between behavior of producers and that of customers, for the period of 20 years. Obviously, DCGEM model comprises seven kinds of field: agriculture and fishing, mining, manufacturing, electricity, gas and water, construction, trade and other services (including transportation, health, and education). To build their model, they also start at CobbDouglas model. In conclusion, in long run, prioritizing of investment in health, and education over public infrastructure has positive relationship with GDP growth, and inverse movement with unemployment rate, and poverty, and inequality. Then, the timing of prioritizing of investment in health, and education over public infrastructure also shows the same result. This recommend for the government that how much more should be invest in education and health; and how much less should be put in infrastructure to generate efficiently economic growth, and mine unemployment rate, poverty, and inequality.

Another work carried out by Nurudeen and Usman (2010) illustrates how related public investment to economic growth in Nigeria is, employed for the period of time from 1970 to 2008, which applies a co-integration 
and error correction method. As a consequence, there is negative relationship between total government expenditure of capital, total government recurrent expenditure, and government expenditures for education and economic growth. Conversely, between government spending for transport and communications, and health and GDP growth show positive association.

After that, Musaba et al., (2013) do research with the same topic, but this research is employed for case of Malawi from 1990 to 2007. By employing co-integration in the context of error correction model (VECM), the authors prove there is mixed result, which depends on aggregate or disaggregate. In whole research, government spending in agriculture, education, health, defense, social protection, transport and communications are considered as independent variables. Particularly, for short-term, it is showed that there is no significant relationship between sectoral government spending and economic growth. Nevertheless, in long term, there is positive significantly relationship between defense spending on agriculture and economic growth. Inversely, spending on education, health, social protection, and transport and communications are related negatively to economic growth.

One of typical paper conducted by IMF (2014) is titled "Economic Growth and Government Spending in Saudi Arabia: An Empirical Investigation" for the period of time from 1969 to 2010, specifically, by Alshahrani, Alsadiq1. That paper is applied for both long term and short term. As a result, it is indicated that private domestic and public expenditure for healthcare moves at the same way with economic growth in the long run. Also, openness to trade and spending in the housing sector push production in the short run. This result is useful for policy makers due to its implication in maximizing government spending's benefit

In Vietnam, there have been a number of papers and studies using a macroeconomic approach in study of the effectiveness of investment in education and training by estimating the contribution or impact of education on whole economic growth. Nguyen Giap (2003) describes the use of production function to estimate the contribution of education and training to Vietnam's economic growth in the two periods 1991-1995 and 1996-2000. Tran Dat (2008) has estimated the impact of various factors, including the educational factor on economic growth of the provinces and cities of Vietnam. These studies focus on the impact of education on economic growth across provinces/cities through a measure of the education level of the labor force, influence of labor force on GDP level and GDP/labor. In Viet Nam, the average level of education of the workforce in almost provinces varies from five to nine years in the 2000-2006 period, so the number of years of schooling increases by one year, it is predicted that the country's income will increase by $1.5-2.7 \%$ /year. Compared with Nguyen Thanh's (2004) microeconomic approach, the estimated real return on investment in human capital was $5.6 \%$ in 2002 , then, the $10 \%$ equivalence with the effect of one year of schooling on total output is about $4 \%$, then, the estimation of the effect of human capital on the GDP derived from the above analysis is quite appropriate in the case of Vietnam. Thus, the study's findings on the positive impact of education spending on economic growth in Vietnam are quite consistent with a number of other studies around the world, such as the study of OECD countries by Wolff (2000), Bils and Klenow (2000). Then, Pham The Anh (2008) uses OLS to test the effect of government expenditures separated according to each kind of fields, for example, education, health, agriculture and forestry, which consists of both recurrent and R\&D spending. After running regression, the author has conclusion that with agriculture and forestry field, recurrent is more positive than $R \& D$ spending. On the other hand, with health, education, and transportation show inverse result, which helps policy makers in distributing state budget. However, the result is conducted from short term, therefore, it cannot true when this is applied for the long term. In addition to examining the relationship between public expenditure and economic growth, contributions from other social resources (from households, socialization, foreign aid) to education are also very important. There has been no study in Viet Nam examining the relationship between total social expenditure on education (including human development index and public expenditure) on growth. In addition, mentioning one macroeconomic variable has not appeared before, for instance, interbank interest rate, inflation rate, or unemployment rate. In the range of this study, one macro variable is taken into account. Because different conditions of economic, political, social, the expenditure on education in one province may have a different effect on economic growth from another province (Aghion et al., (2009)). This paper contributes to assessment of education spending structure's evaluation as well the importance of each capital source in whole society into effectiveness of education's investment.

Moreover, thanks to education, people can raise living standard by achieving good skills, knowledge to enjoy their lives (Phung (2012) and Pham (2016)). On the other hand, education is also an investment field, requiring investment in capital and time to improve the level of productivity. So in fact, the government in a lot of countries around the world has tendency to spend much more on education. That is the reason why there is a variety of studies have tried to express the positive relationship between education spending and economic growth. Research on education expenditure can be divided into two main approaches. The first one approaches at a macro level, studying the relationship between public expenditure in education and economic growth. The second one approaches at a micro level, studying the relationship between household expenditures for education and economic growth.

Until now, in Vietnam, there are some papers taking about the relationship between public investment in education as well as its performance and health and GDP per capital. However, the effectiveness of these research 
is not high because they have not updated new models to describe the impact of government expenditure for education and human resource quality on economic growth in scale of whole country. As a result, building the model to describe the relationship between public investment for education and for health and GDP growth is necessary to show contributing proportion of education and health in economic growth.

\subsection{Public spending for Education on Human Development Index (HDI).}

Human development definition exposed in Human Development Report (HDR) in 1990, then Human Development Index (HDI) was introduced to evaluate quality of human, however, obviously HDI could not be indicator as effective as GDP. Indeed, HDI plays an important role in foreign investment decision of investors because it can be said that HDI demonstrates qualification of labor resource as well as potential development of that invested country. Exogenous factors like public expenditure for education separated many categories like regular, recurrent, and development and investment spending are related closely to human quality and labor force performance including both skill, knowledge and attitude. HDI can be expressed through decent standard of living, ability to access knowledge, long and healthy life. Also, there are some impacts on HDI like life expectancy at birth, adult literacy rate, and GDP per capital. It is undeniable that investment in education from the government is considered as a key for human capital.

People who gain higher education or better schooling will contribute efficiently in economic growth and social responsibility (Pfeifer (2007)). Then, also according to this research, the author can conclude that there is positive correlation between better education and higher living standard. In addition, learning of each one is related positively to satisfaction of life and health condition of people (Schuller, 2007), which is called as non-monetary benefit of education, and definitely, the other is monetary outputs like GDP growth for instance. There are also a lot of evidence to support for the argument that education moves at the same way with health status, and standard living (Goldberg and Smith, 2007; Stiglitz et al., (2009); Mackenbach, 2006; Stone et al., (2008)).

Upgrated lastestly, Ionescu et al., (2013) carried out a work of investment in education and quality of life, starting with consideration of positive relationship between economics and education per individuals. Consequently, the study provides a positive relationship between investment in education and quality of life which is explained by Human Development Index, Economist Intelligence Unit Quality of Life Index (EIUQOLI), and Satisfaction with Life Scale (SLS). In addition, independent variables to support for investment in education given in this study were both public and private expenditure on educational institutions per student, and gross domestic expenditure on research and development. In this paper, the author employed a sample of 27 countries in Europe Union for period of three years, which were collected from Eurostat database. However, in this research, the author used multiple methods of regression with dependent variables of Quality of Life represented by HDI, EIUQOLI, and SLS. This work contributed a lot in further research with the same consideration as well as helped policy makers to rearrange public expenditure structure for both education and other vital fields to raise people's standard of living or HDI.

Another work with the same idea conducted by Požega mentioned effect of both education and social expenditures and HDI on GDP growth. Firstly, they analyzed linear correlation among HDI, average time of education, and social expenditure, then they came into conclusion that three variables were mutually positive relationship. Secondly, when employing multiple linear correlation where GDP per capita was dependent variable, and HDI, average time of education and social expenditures were explanatory. Consequently, only HDI had positive relationship with GDP per capital, whereas, average time of education spending moved negatively with dependent variable and the other had no significant effect on GDP per capital. In general, although the authors did not give exact amount of expenditure for both education and society, it was undeniable that they considered education investment as an important impact on HDI as well as GDP per capital.

In Vietnam, there is unreasonable when public expenditures for education stays high, even makes up an overwhelming amount of government budget besides health, and public transportation infrastructure, HDI has not been improved over recent decade. Specifically, until 2014, according to The Vietnam Academy of Social Sciences in collaboration with the United Nations Development Program who released report of human development in Vietnam in 2015, Vietnam stays at the position of 116/188 with consideration of whole world, which means this level is higher than average one. However, this growth rate is not stable when average growth rate of HDI only increases $1.07 \%$ from 1980 to 2014, which is lower than a group of country having average HDI that is $1.23 \%$. In addition, this growth rate of Vietnam is lower than average rate of ASEAN zone, $1.29 \%$. This proves that HDI growth rate in Vietnam is decreasing slowly. Consequently, foreign investors, normally, take into account this phenomena to make investing decision in Vietnam whether or not. To solve this issue, according to Ms. Mehta, to raise or at least to maintain HDI growth rate, the Vietnamese government should invest more in human capital. If not, gained benefits from international market or foreign direct investment is limited, therefore, investing into human's quality helps to raise competitive advantages with countries in Asia zone as well as over the world. However, in reality, the government has spent more money in education investment, whereas, HDI growth rate does not increase. That is the reason why in this area of study, the relationship between investment in education 
and HDI is mentioned. To the best our knowledge, this is the first research of the impact of HDI on economic growth.

\section{Methodology}

\subsection{Research question}

Our goal when doing the topic is estimating the impact of government expenditure for education on economic growth. In addition, performance of public investment for education such as enrolment number of some schooling stage and inflation rate are included in the model. After taking into account the previous papers as well as theoretical studies, the main points are how the enrolment numbers of some kinds of schooling stage, government capital and regular expenditure for education, human capital quality, and inflation rate influence GDP growth. This means that they are statistically significant on GDP growth or not. In addition, it is estimated that enrolment numbers of each schooling stage, human capital resource, and government capital and regular expenditure for education have positive relationship with GDP growth. On the other hand, inflation rate is predicted to show inverse relationship with GDP growth.

Besides, that whether enrolment numbers of each schooling stage, and government capital and regular expenditure for education are statistically significant on human capital quality (HDI as a proxy) or not and how they are related to HDI is one of our issues estimated. Finally, because of the effect of health on human capital quality, percentage of government expenditure for health is also added to estimate its impact on economic growth. Similarly, the issue is that whether percentage of government expenditure for health is statistically significant on GDP growth or not and how it is related to GDP growth.

\subsection{Data and sampling method}

Our sample consists of 16 observations which is period of 16 years (from 2000 to 2015). To increase the confidence of the research, we collect date from to various sources. The table bellow shows more details of data:

Table 1: Data Collection

\begin{tabular}{|l|l|l|l|}
\hline Name & Unit & Denoted Variables & Source \\
\hline GDP growth & $\%$ & GDPG & World Bank \\
\hline Percentage of high school graduation & $\%$ & HSGRA & GSO \\
\hline Enrolment number of in pre-primary education & Number & ENRPP & UNESCO \\
\hline Enrolment number of in primary education & Number & ENRP & UNESCO \\
\hline $\begin{array}{l}\text { Enrolment number of in lower secondary } \\
\text { education }\end{array}$ & Number & ENRLS & UNESCO \\
\hline $\begin{array}{l}\text { Enrolment number of in upper secondary } \\
\text { general }\end{array}$ & Number & ENRUS & UNESCO \\
\hline $\begin{array}{l}\text { Government budget for education(Capital } \\
\text { expenditure) }\end{array}$ & Billion VND & CAPEX_EDU & Ministry of Education \\
\hline $\begin{array}{l}\text { Government budget for education(Regular } \\
\text { expenditure) }\end{array}$ & Billion VND & REEX_EDU & Ministry of Education \\
\hline HDI (Human capital quality) & Unit & HDI & UNDP \\
\hline
\end{tabular}

This sample is applied for period of 16 years when according to General Statistics Organization (GSO), the number of public and private universities as well as colleges increases dramatically from 148 to 347 , and from 30 to 89 , respectively. This means that there will be change for this period to create enough infrastructure for education and training program. Furthermore, until now, some kind of typical data of 2016 have not completed, therefore, we exclude this year for sample. To sum up, after solving data, we will run regression for the sample of 16 years from 2000 to 2015 .

\subsection{Specification model \\ Theoretical model}

In fact, the research of impact of government expenditure for education on economic growth reflects not only real expenditure situation of the State, but also relates to the quality of policies in distributing budget in each category. The fundamental theory that approaches initially GDP growth based on production function is Solow (1956). This is considered as a classic model and fundamental theorical model which is used as background to develop for further. Originally, Solow (1956) takes into account three exogenous variables to explain the impact on income per capital: rate of savings, population growth, and technological progress. In this work, we will concentrate on the implication of Solow model when applied for cross-country data.

By assuming that in neoclassical production function model, return to capital decreases gradually. Particularly, Solow (1956) is established in continuing time world and there is no intervention of government and international trading. In accordance with Cobb-Douglas function, capital and labor are paid marginal products. Then, Solow 
(1956) gives the following model:

$$
Y(t)=K(t)^{\alpha}(A(t) L(t))^{1-\alpha}
$$

Where $\mathrm{Y}$ is output, $\mathrm{K}$ is capital and $\mathrm{L}$ is labor, $\mathrm{A}$ is technological progress, $\mathrm{t}$ is time, and $\alpha$ is elasticity of output with capital. Noted that $0<\alpha<1$ and $\mathrm{L}$ and $\mathrm{A}$ are assumed to increase exogenously with rate $\mathrm{n}$ and $\mathrm{g}$, respectively. Then,

$$
\begin{aligned}
& L(t)=L(0) e^{n t} \\
& A(t)=A(0) e^{g t}
\end{aligned}
$$

Therefore, $\mathrm{A}(\mathrm{t}) \mathrm{L}(\mathrm{t})$ grows with rate of $(\mathrm{n}+\mathrm{g})$. Then, derivatives of $\mathrm{K}$ according to time is proved as follow:

$$
k^{\prime}(t)=s \cdot y(t)-\delta \cdot k(t)=s k^{\alpha}(t)-(n+g+\delta) k(t)
$$

Where $s$ is rate of savings, $k$ is stock of capital per effective unit of labor $(k=K / A L)$, y is output per effective unit of labor $(\mathrm{y}=\mathrm{Y} / \mathrm{AL})$, and $\delta$ is depreciation level.

The function implies that $\mathrm{k}^{\prime}(\mathrm{t})$ converges to steady-state $\mathrm{k}^{*}$ which is defined in the function of $s k^{* \alpha}=$ $(n+g+\delta) k^{*}$ then:

$$
k^{*}=\left(\frac{s}{n+g+\delta}\right)^{\left(\frac{1}{1-\alpha}\right)}
$$

It can be seen from the equation that steady-state of capital-labor ratio moves at the same way with rate of savings and is related negatively with population growth. This means higher rate of savings makes country richer, meanwhile, higher population rate decreases standard of living. In general, Solow model concludes that income per capital in poor countries tends to coverage or catch up that one in rich countries if rate of savings is the same. However, it is the fact that this level is different in different countries and regions because of diversification of financing policy, culture, and political status. For example, some developing countries like Vietnam have tendency to invest more in human capital, therefore, rate of savings will be different from others. However, one main limitation of the model is that Solow (1956) does not take into account human capital, meaning that there is lack of endogenous factor. Indeed, in production function, human capital or labor quality plays an important part in economic growth. That is the reason why Mankiw, Romer, and Weil (1992) do the research to argue the result of Solow model by taking into account accumulating of both human capital and physical capital with idea that accumulation of human capital may be correlated with rate of savings or population growth. Finally, the authors jump into conclusion that adding accumulation of human capital decreases the explained impact of rate of savings or population growth. The function which the authors give after proving process is:

$$
\ln \left[\frac{Y(t)}{L(t)}\right]=\ln [A(0)]+g(t)-\frac{\alpha+\beta}{1-\alpha-\beta} \ln (\alpha+\beta+\delta)+\frac{\alpha}{1-\alpha-\beta} \ln (s k)+\frac{\beta}{1-\alpha-\beta} \ln (s h)
$$

Where $\mathrm{h}$ is human capital and $\beta$ is growth rate of human capital, and the others have been explained already above.

These works and functions creates a lot of questions that which factors affect human capital and how to improve that; and one of popular aspect is government expenditure. In reality, in each country, government budget is spent for a variety of fields such as education, health, transportation, etc..., so approaching method of authors will be variable. Some focus on expenditure following purpose, meanwhile, some separate by each field. However, major goal is to try to prove the relationship between government expenditure for each field and GDP growth. In addition, through education, health, quality of human can be improved significantly. Therefore, some empirical frameworks as well as models are given by some researchers.

Firstly, Amadi et al., (2013) conclude the function to demonstrate the impact of public expenditure on economic growth, with inclusive of education, health that raise human capital on GDP. The function is given as follows

$$
P D B R=f(T R C P s, R D C P s, \text { OESPs, EDUPs, htps })
$$

Then, Musaba et al., (2013) also establish a model to show the relationship between government expenditure and economic growth using log function form, which mentions both short term and long term effect.

The above models are applied mostly by further researchers because of their high application as well as degree of accuracy when they use natural log functional form to illustrate huge numbers such as GDP, capital for education, health, transportation and communication. We will run regression for our topic based on these models with adjustment and diversify because each country there will be different from culture, political situation, as well as economic developing policy.

\section{Methodology}

Firstly, we demonstrate measurement of education as indirect method before approaching main concern of education's effect on GDP growth, which is called performance of investment for education. In accordance with macro point of view, with organization or corporation, performance of investment for education is expressed through additional labor productivity, profit created for them, or the number of products that one person can make. Fuente (2003) estimates that if average number of schooling year increases by one year, average productivity of Europe Zone increases $6.2 \%$ on average and by $3.1 \%$ in long term. In addition, when concerning whole economy, 
estimation of performance of education's investment including aspects also brings significant diversification, for example, such as real GDP, GDP growth, GDP per capita, or income per capital. Particularly, Bills and Klenow (2000), Wolff (2000), Brossard and Foko (2006) as well as Hanushek and Woessmann (2008) prove that investment for education is related positively to GDP growth, whereas, average schooling years, one measurement of education's performance, has positive relationship with degree of economic growth. Moreover, different authors will have different approaches to performance of investment for education such as total primary school pupil enrolment, primary pupil-teacherset ratio (Ifionu, et al., 2013).

However, after concerning the model derived from theoretical frameworks mentioned above such as Musaba et al., (2013) and cultural environment, economic condition, especially political status of Vietnam, we decide to adjust when building the estimated models as following:

Model 1: $\mathrm{HDI}=\beta_{1}+\beta_{2} \ln (\mathrm{ENRLS})+\beta_{3} \ln (\mathrm{ENRP})+\beta_{4} \ln (\mathrm{ERNPP})+\beta_{5} \ln (\mathrm{ENRUS})+\beta_{6} \ln (\mathrm{HSGRA})+$ $\beta_{7} \ln (\mathrm{CAPEXEDU})+\beta_{8} \ln (\mathrm{REEXEDU})+\varepsilon$ Model $2: \ln (G D P G)=\beta_{1}+\beta_{2} \ln ($ ENRLS $)+\beta_{3} \ln ($ ENRP $)+\beta_{4} \ln ($ ERNPP $)+\beta_{5} \ln ($ ENRUS $)+$

$\beta_{6} \ln ($ HSGRA $)+\beta_{7} \ln ($ CAPEXEDU $)+\beta_{8} \ln ($ REEXEDU $)+\beta_{9} H D I+\beta_{10} \ln ($ health $)$

whereas variables are enrolment number of lower secondary school (ENRLS), enrolment number of upper secondary school (ENRUS), enrolment number of pre-primary school (ENRPP), enrolment number of primary school (ENRP), percentage of high school graduation (HSGRA), capital and regular expenditure of government budget for education (CAPEX_EDU and REEX_EDU), percentage of government expenditure for heath (HEALTH), HDI, and GDP growth.

\section{Quantitative Analysis}

4.1. Descriptive statistics

Totally, there are 10 variables including dependent variables as explained in equation (6) and (7). Before analyzing correlation as well as doing hypothesis testing, overview of whole data in the sample will be provided by the following table.

Table 2: Descriptive data

\begin{tabular}{|l|l|l|r|r|r|r|r|r|r|r|}
\hline & ENRLS & ENRUS & ENRP & \multicolumn{1}{l|}{ ENRPP } & HSGRA & CAPEX_EDU & REEX_EDU & HEALTH & \multicolumn{1}{c|}{ HDI } & \multicolumn{1}{c|}{ GDPG } \\
\hline Mean & 5725032 & 2665909 & 7837717 & 2740911 & 92.125 & 16567.07 & 79031.54 & 2.445625 & 0.634188 & 6.382445 \\
\hline Median & 5812890 & 2715265 & 7376331 & 2652102 & 92 & 12015 & 58378.5 & 2.345 & 0.637 & 6.33631 \\
\hline Maximum & 6670714 & 3111280 & 10063025 & 3760935 & 99 & 41376.38 & 199093.9 & 3.87 & 0.683 & 7.547248 \\
\hline Minimum & 4869839 & 1975836 & 6745016 & 2113594 & 80 & 2360 & 10356 & 1.39 & 0.576 & 5.247367 \\
\hline Std. Dev. & 677317.9 & 327213.3 & 1089067 & 577798.8 & 5.475704 & 13634.62 & 63531.39 & 0.954205 & 0.034925 & 0.728162 \\
\hline Skewness & -0.01129 & -0.487224 & 0.943387 & 0.462946 & -0.52031 & 0.55004 & 0.609142 & 0.376033 & -0.1876 & 0.035437 \\
\hline Kurtosis & 1.457531 & 2.391843 & 2.447413 & 1.868183 & 2.757131 & 1.848191 & 1.986027 & 1.632591 & 1.764854 & 1.997524 \\
\hline Jarque-Bera & 1.586481 & 0.879602 & 2.576848 & 1.425524 & 0.761262 & 1.691227 & 1.674905 & 1.623608 & 1.110904 & 0.673321 \\
\hline Probability & 0.452377 & 0.644165 & 0.275705 & 0.490288 & 0.68343 & 0.429294 & 0.432812 & 0.444056 & 0.573813 & 0.714151 \\
\hline Sum & 91600508 & 42654552 & $1.25 E+08$ & 43854579 & 1474 & 265073.1 & 1264505 & 39.13 & 10.147 & 102.1191 \\
\hline Sum Sq. Dev. & $6.88 E+12$ & $1.61 E+12$ & $1.78 E+13$ & $5.01 E+12$ & 449.75 & $2.79 E+09$ & $6.05 E+10$ & 13.65759 & 0.018296 & 7.953302 \\
\hline Observations & 16 & 16 & 16 & 16 & 16 & 16 & 16 & 16 & 16 & 16 \\
\hline
\end{tabular}

It can be seen from the table that GDP growth runs around in the range of from $5.24 \%$ to $7.54 \%$; its mean is $6.38 \%$ that is higher insignificantly than median. Then, mean of enrolment number of lower secondary school, enrolment number of upper secondary school, enrolment number of pre-primary school, enrolment number of primary school is $5.7 ; 2.67 ; 2.7 ; 7.8$ million, respectively. After that, the average percentage of high school graduation is $92.125 \%$, which is not really good, which is the result of the change in statutes of graduation examination. Next, human capital quality calculated by HDI is quite low when its mean is 0.634 , therefore, this index should be concentrated on and improved. Furthermore, regular expenditure in total government expenditure for education is much higher than that of capital expenditure when the former's mean is 79,031.54 million VND and the later's one is only 16,567.07 million VND, meaning that the state have still spent much money on regular account for education. As mentioned above, normally, the government spends approximately $20 \%$ of total budget for education, whereas, in this table, the percentage of government budget for health is around $2.445 \%$ that is nearly one tenth of that for education.

In addition, skewness and kurtoris shows whether the sample is normally distributed or not. Therically, when skewness comes to 0 and kurtoris goes to 3, the sample is normally distributed. In fact, from the descriptive date, skewness of almost variables is nearly 0 , meanwhile, kurtoris is quite far from 3 , which means the sample in this research may be not normally distributed. However, to use OLS method, we assume that our sample is normally 
distributed and this phenomenon will be considered as limitation.

\subsection{Correlation analysis}

Before jumping into result of significant test, we want to show correlation matrix which is summarized as follow:

Table 3: Correlation Matrix of Model 1

\begin{tabular}{|c|c|c|c|c|c|c|c|c|}
\hline & HDI & LOG(ENRLS) & LOG(ENRP) & LOG(ENRPP) & LOG(ENRUS) & LOG(HSGRA) & $\begin{array}{c}\text { LOG(CAPEX } \\
\text { EDU) } \\
\end{array}$ & \begin{tabular}{|c|} 
LOG(REEX \\
EDU $)$ \\
\end{tabular} \\
\hline HDI & 1.000000 & & & & & & & \\
\hline LOG(ENRLS) & -0.784668 & 1.000000 & & & & & & \\
\hline LOG(ENRP) & -0.817242 & 0.423160 & 1.000000 & & & & & \\
\hline LOG(ENRPP) & 0.973776 & -0.868196 & -0.698218 & 1.000000 & & & & \\
\hline LOG(ENRUS) & 0.500587 & 0.005440 & -0.889908 & 0.326846 & 1.000000 & & & \\
\hline LOG(HSGRA) & 0.478067 & -0.568556 & -0.034479 & 0.540592 & -0.236800 & 1.000000 & & \\
\hline LOG(CAPEX_EDU) & 0.994452 & -0.792786 & -0.833246 & 0.971499 & 0.517063 & 0.458701 & 1.000000 & \\
\hline LOG(REEX_EDU) & 0.998333 & -0.773485 & -0.832376 & 0.967945 & 0.524777 & 0.465718 & 0.997319 & 1.000000 \\
\hline
\end{tabular}

It can be seen from the table that enrolment number of pre-primary school, government expenditure for education including capital expenditure and regular have strong positive relationship with dependent variable as HDI, whereas, enrolment number of upper secondary school and percentage of high school graduation are positive related to HDI but weak. On the other hand, enrolment number of lower secondary school and enrolment number of primary school indicate quite strong negative correlation with HDI. This gives an overview how explanatories correlate to HDI.

In addition, government expenditure for education related to both capital expenditure and regular one show strong positive, positive, and negative with enrolment number of pre-primary school, enrolment number of upper secondary school and percentage of high school graduation, and enrolment number of primary school, respectively. One significant point is the correlation of percentage of high school graduation with other variables is quite low or even negative, which means it is estimated that this kind of variable is not significant. The result of the test will be showed later.

Then, we reveal the correlation matrix among variables of the main model in our research "Government expenditure for education and health and Economic growth".

Table 4: Correlation Matrix of Model 2

\begin{tabular}{|c|c|c|c|c|c|c|c|c|c|c|}
\hline & LOG(GDPG) & $\mathrm{HDI}$ & LOG(ENRLS) & LOG(ENRP) & LOG(ENRPP) & LOG(ENRUS) & LOG(HSGRA) & $\begin{array}{l}\text { LOG(CAPEX } \\
\text { EDU) }\end{array}$ & $\begin{array}{l}\text { LOG(REEX } \\
\text { EDU) }\end{array}$ & LOG(HEALTH) \\
\hline LOG(GDPG) & 1.000000 & & & & & & & & & \\
\hline $\mathrm{HDI}$ & -0.529404 & 1.000000 & & & & & & & & \\
\hline LOG(ENRLS) & 0.726259 & -0.784668 & 1.000000 & & & & & & & \\
\hline LOG(ENRP) & 0.377481 & -0.817242 & 0.423160 & 1.000000 & & & & & & \\
\hline LOG(ENRPP) & -0.584418 & 0.973776 & -0.868196 & -0.698218 & 1.000000 & & & & & \\
\hline LOG(ENRUS) & -0.102993 & 0.500587 & 0.005440 & -0.889908 & 0.326846 & 1.000000 & & & & \\
\hline LOG(HSGRA) & -0.235495 & 0.478067 & -0.568556 & -0.034479 & 0.540592 & -0.236800 & 1.000000 & & & \\
\hline LOG(CAPEX_EDU) & -0.519051 & 0.994452 & -0.792786 & -0.833246 & 0.971499 & 0.517063 & 0.458701 & 1.000000 & & \\
\hline LOG(REEX_EDU) & -0.512671 & 0.998333 & -0.773485 & -0.832376 & 0.967945 & 0.524777 & 0.465718 & 0.997319 & 1.000000 & \\
\hline LOG(HEALTH) & -0.639948 & 0.933131 & -0.893163 & -0.679430 & 0.969744 & 0.315494 & 0.451337 & 0.937211 & 0.927445 & 1.000000 \\
\hline
\end{tabular}

Similarly, we also have correlation matrix in order to show the correlation among variables in the main model.

Firstly, it can be seen that almost variables indicate negative correlation with GDP growth, for example, enrolment number of upper secondary school, enrolment number of pre-primary school, percentage of high school graduation, government expenditure for education including both capital expenditure and regular expenditure, and HDI as a proxy of human capital quality. Nevertheless, enrolment number of lower secondary school performs high positive correlation with GDP growth, while both enrolment number of primary school demonstrate positive correlation but weak. Typically, it is necessary to consider mostly variables named government expenditure for education (including capital expenditure and regular expenditure). As a result, the table shows the same compared to the above correlation matrix table when there is an strong positive correlation between them and enrolment number of pre-primary school.

From the table, basically, with independent variables such as capital expenditure and regular expenditure for education, and inflation perform the same result as the second correlation matrix table. However, there is one significant point here is the appearance of government expenditure for health (percentage of GDP) as an impact on economic growth. The table shows that there is strong positive correlation between public investment for education and that of health (percentage of GDP). The test will be illustrated in the next session. 


\subsection{Regression Results}

The impact of education investment by government on human development index (HDI)

By running Eview 9 version, we have the result of multiple regression of the relationship between government expenditure for education as well as education's performance and human quality with HDI as a proxy. The table of result is shown below:

The estimated regression is proved as follow:

$$
\begin{aligned}
\widehat{H D} I=1.18- & 0.0033 \ln (E N R L S)-0.06 \ln (E N R P)+0.04 \ln (E R N P P)-0.03 \ln (E N R U S) \\
& +0.01 \ln (H S G R A)-0.03 \ln (C A P E X E D U)+0.06 \ln (R E E X E D U)
\end{aligned}
$$

$\mathrm{t}$-statistic respectively are: $1.687436,-0.321085,-2.235334,2.524329,-1.478709,1.175843,-3.513099,7.858824$

$\mathrm{R}^{2}$, Adjusted $\mathrm{R}^{2}$ are: 0.999074 and 0.998264

\subsection{Estimated Regression of Model 2}

The estimated regression of model 2 is expressed as bellow:

$$
\begin{aligned}
\ln (\widehat{G D P} G)=- & 64.49+26.7 H D I+1.74 \ln (E N R L S)+3.88 \ln (E N R P)-2.92 \ln (\text { ENRPP }) \\
& +0.69 \ln (\text { ENRUS })-0.87 \ln (H S G R A)+1.85 \ln (\text { CAPEXEDU })-1.78 \ln (\text { REEXEDU }) \\
& -0.0049 \ln (\text { HEALTH })
\end{aligned}
$$

t-statistic respectively are: $-2.683285,2.951959,5.291758,3.790592,-4.766090,1.034175,-2.506931,5.911545$, $-3.705134,-0.032487$

$\mathrm{R}^{2}$, Adjusted $\mathrm{R}^{2}$ are: 0.959421 and 0.898552

The relationship between public investment for education and for health and economic growth.

We check Multicollinearity, Heteroskedasticity and Autocorrelation errors.

In order to correct the problem of Heteroskedasticity and Autocorrelation, the final estimated regression is rewritten as follows:

$$
\begin{aligned}
\ln (\widehat{G D P G})=- & 53.82+24.01 H D I+1.88 \ln (E N R L S)+3.52 \ln (E N R P)-3.09 \ln (E N R P P) \\
& +0.36 \ln (E N R U S)-0.69 \ln (H S G R A)+1.95 \ln (C A P E X E D U)-1.77 \ln (R E E X E D U) \\
& +0.02 \ln (\text { HEALTH })+0.79 A R(2)+0.0002 \sigma^{2}
\end{aligned}
$$

t-statistic respectively are $-2.901016,3.082990,9.699927,4.374525,-8.453213,0.785207,-2.705915,8.078208$, $-4.470401,0.211664,3.782229,1.607118 ; \mathrm{R}^{2}$ is 0.979975 and Adjusted $\mathrm{R}^{2}$ is 0.924908 .

\section{Conclusion}

\subsection{Summary and Conclusion}

By using OLS method applied for the sample of 16 observations, our estimated regression of HDI shows that enrolment number of pre-primary school, capital and regular expenditure of government budget for education are statistically significant on human capital quality (HDI), meaning that it is reliable when saying that they directly effect on HDI. Particularly, enrolment number of pre-primary school and regular government spending for education have positive relationship with HDI, meanwhile, capital spending for education shows negative relationship. On the other hand, the others are not statically significant on human capital quality. This result is not right as expected when in this research we expect that all enrolment number of schooling stages and government expenditures for education including both capital and regular component are statistically significant on HDI and have positive relationship with HDI.

After that, the model of the impact of public investment for education on GDP growth indicates specific results. In accordance with regression and hypothesis testing, it is proved that enrolment number of lower secondary school, enrolment number of pre-primary school, enrolment number of primary school, percentage of high school graduation, both capital and regular spending of government budget for education, and HDI are statistically significant. Where, enrolment number of lower secondary school, enrolment number of primary school, capital expenditure of public budget for education, and HDI are related positively to GDP growth. Typically, enrolment number of primary school influence most on GDP growth when if it increases by $1 \%$, GDP growth rises $3.91 \%$. On the other hand, enrolment number of pre-primary school, percentage of high school graduation, and regular spending for education move with an opposite way with GDP growth. Consequently, there are some similar results with previous studies, for example, Barro (1991) also shows the positive relationship between human capital and economic growth; or Yi and Kocherlakota (1996) also prove that public investment for education is related positively to GDP per capita (a representor of economic growth); or Nonneman and Vanhoud (1996) conclude that human capital and secondary enrolment number representing performance of investment of education have relationship with GDP growth rate. Besides, percentage government expenditure per GDP for health is proved to not affect GDP growth when combining it in the model with government expenditure for education and HDI, which is not similar with previous studies and our expectation. However, when testing only influence of percentage government expenditure per GDP for health on GDP, there is enough confidence to infer that this factor is statistically significant on GDP growth. This consequence proves that in whole economy, the 
government should pay more attention on education.

\subsection{Implication and recommendation}

Originally, the topic provides the empirical and quantitative model to illustrate the relationship between government expenditure for education and economic growth, which helps policy makers know which variable affects GDP growth and which variable is positively related to economic growth. Therefore, they can create policies to fit and improve the current situation of Vietnam, especially budget spending efficiency. In addition, the study also provides some new proofs to evaluate the performance of investment for education, and make comparison between the impact of government expenditure for education and health on GDP growth. It is recommended that the government should still spend more proportion of budget for education than that for health. Also, currently, the government still spends a large percentage of budget for regular account, whereas, that for capital is not much, consequently, the distribution of budget should be considered more to maximize its performance. In addition, quality of foundation schooling stages like primary school, and lower secondary school influence much economic growth and human capital resource. That is the reason why they should be concentrated on. In addition, this helps the further researchers have background to consider it as a reference when taking into account the performance of public investment for health. Last but not least, the main model shows that regular expenditure of government budget for education is related negatively to GDP growth, while regular account makes up a majority in total, therefore, models are also useful for policy makers when restructuring the budget to develop both human capital qualify and economic growth.

\subsection{Limitation}

Although we put much effect both knowledge and time to do the research, there are still unavoidable mistakes and limitations.

Firstly, during the process, some typical errors like multicollinearity, and autocorrelation are proved to exist, which comes from inaccurate variables choosing. For example, enrolment number of lower/upper secondary school, enrolment number of pre-primary/primary school, or even percentage of high school graduation have not been representors exactly to reflect efficiency of public investment for education. However, in the scale of this topic, we correct the autocorrelation for the first model, the other is not corrected limited time and knowledge. Although there are many solutions to redeem these errors like changing in functional form, running typical regression for each type of error, we will do it in the further research because of time.

Secondly, there is a little difference between correlation matrix and Eview's result, however, we only try to correct for the first model. If using similar method for model 1 , all independent variables become insignificant. That is the reason why we add this problem as limitation, which comes from breaking the OLS assumption that is the sample is normally distributed.

Thirdly, after running the second model with HDI as independent variable and realizing that there is conflict between correlation matrix and Eview's result, we try to solve the problem by replacing HDI into HDIf (HDI forecast), but Eview cannot compute. In order to solve this issue, it is suggested dropping dummy variables or constant term. However, after trying above solutions, we do not take the appropriate result. Consequently, we also add it as limitation.

Fourthly, we focus on the structure of government expenditure, including capital and regular spending for national scale, however, we have not taken into account components of government budget. Indeed, the sources of state budget is diversified and each province will have different policy in budget distribution. For example, it comes from ODA, borrowing by issuing bonds into domestic and foreign market. It is highly recommended that the sources of government capital as well as situation of public expenditure of each province in Vietnam should be taken into account for further research.

Last but not least, it is proved that macroeconomics variables like inflation rate, exchange rate, lending rate, government bond rate, or interbank rate, etc that should be as macro variables. However, in this research, adding inflation rate as macro variable in GDP growth model reduces importance of education's investment as well as its performance on GDP growth. To explain this problem, it results from independent variables choice, especially the performance of education's public investment. Therefore, it is highly suggested that further authors should pick up other enrolment factors or percentage of relative education's components.

\section{Reference}

Barro. R.J. (1991). "Economic growth in a cross section of countries". Quarterly Journal of Economics 160(2), 407-44. https://academic.oup.com/qje/article-abstract/106/2/407/1905452

Benhabib, J., \& Spiegel, M. (1994). "The Role of Human Capital in Economic Development: Evidence from Aggregate Cross-Country Data". Journal of Monetary Economics, 34(2), 143-173. https://www.sciencedirect.com/science/article/abs/pii/0304393294900477

Bils, M., and Klenow, P. (2000). Explaining Differences in Schooling Across Countries. University of Rochester. 
Goldberg, J., and Smith, J. (2007). The Effects of Education on Labor Market Outcomes. http://econweb.umd.edu/ goldberg/docs/Goldberg_and_Smith_AEFA.pdf

Lucas, R. (1988). On the Mechanics of Economic Development. Journal of Monetary Economics, 22, 3-42.

M.Bils and P. Klenow. (2000). Does Schooling Cause Growth? American Economic Review, 90-5:1 160-1183.

Solow. (1956). The Quarterly Journal of Economics. Vol. 70, No. 1 (Feb., 1956), pp. 65-94 Published by: The MIT Press

Mackenbach, J. P. (2006). Health Inequalities: Europe in Profile, UK Presidency of the EU.

Mankiw, and David N. Weil. (1992). A contribution to the empirics of economic growth. Quarterly Journal of Economics, 107, no. 2: 407-37.

Mankiw, G. (1992). A Contribution to the Empirics of Economic Growth. Quarterly Journal of Economics, Vol. 107, pp. 407-437.

Musaba, EC, Chilonda P., \& Matehaya. (2013). The Sectoral Impact of Government Expenditure on Economic Growth in Malawi. Journal of Economics and Sustainable Development-1700 ISSN (paper) ISSN 22222855 (online) Vol.4. No. 2.

N. Gregory and David Romer. (1992). A contribution to the empirics of economic growth. Quarterly Journal of Economics, 107( 2), 407-37.

Narudeen, A. \& Usman, A. (2010). Government Expenditure and Economic Growth in Negiria, 1980-2007 Disaggreated Analysis. Business and Economics Journal, volume 2010: JSX-4 (online) Available.

Nguyen Duc Thanh, 2004. Private and Social Returns to Investments in Education in Vietnam over Time: 1993 2002, MDE thesis, NEU.

Nonneman,W.and Vanhoudt,P. (1996). A further augmentation of the Solow model and the empirics of economics growth for OECD countries. Quarterly Journal of Economics, Vol. 11, pp. 943-953.

Omotor, D.G. (2004). Federal Government Expenditure in Education. Abraka Journal of Social Sciences 9(2): 105-110.

Pfeifer, A. (2007). Good Practices in Basic Education in Latin America. OECD Conference, Istanbul, Turkey.

Pham The Anh (2008). Analysis of government expenditure structure and economic growth in Vietnam, NC03/2008. The Center of Economic Research and Policy, The University of Economics and Business, The Vietnam National University.

Pritchett . (1996). Where Has All the Education Gone?. Policy Research Working Paper Series 1581, World Bank, Washington, DC

Pritchett, L. (2001). Where has all the education Gone?. World Bank Economic Review, 15, 367-91.

Romer. (1986). Increasing Returns and Long-Run Growth. Journal of Political Economy, 94(5), 1002-37.

Schuller, T. (2007). Understanding the social outcomes of learning. Second OECD World Forum on Statistics, Knowledge and Policy, Istanbul, Turkey.

Solow. (1956). A Contribution to the Theory of Economic Growth. Quarterly Journal of Economics, 70(1), pp: $65-94$.

Stiglitz etal. (2009). Report by the Commission on the Measurement of Economic Performance and Social Progress. www.stiglitz-sen-fitoussi.fr.

Stone et al., (2008). Exploring the Socio-Economic Gradient. In Daily Colds and Flu, Headaches, and Pain, mimeo. 